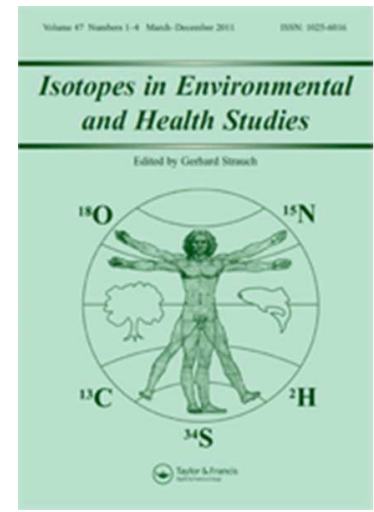

\title{
Deuterium dilution technique for body composition assessment: resolving methodological issues in children with moderate acute malnutrition
}

\begin{tabular}{|c|c|}
\hline Journal: & Isotopes in Environmental \& Health Studies \\
\hline Manuscript ID & GIEH-2016-0113.R1 \\
\hline Manuscript Type: & Original Article \\
\hline Date Submitted by the Author: & $\mathrm{n} / \mathrm{a}$ \\
\hline Complete List of Authors: & $\begin{array}{l}\text { Fabiansen, Christian; University of Copenhagen, Department of Nutrition, } \\
\text { Exercise and Sports; Médecins Sans Frontières - Denmark; Alliance for } \\
\text { International Medical Action } \\
\text { Yaméogo, Charles; University of Copenhagen, Department of Nutrition, } \\
\text { Exercise and Sports; UFR-SVT/Université de Ouagadougou, Centre de } \\
\text { Recherche en Sciences Biologiques, Alimentaires et Nutritionnelles; } \\
\text { Ministère des Enseignements Supérieurs, de la Recherche Scientifique et } \\
\text { de I'Innovation, Institut de Recherche en Sciences de la Santé } \\
\text { Devi, Sarita; St John's Research Institute, Division of Nutrition } \\
\text { Friis, Henrik; University of Copenhagen, Department of Nutrition, Exercise } \\
\text { and Sports } \\
\text { Kurpard, Anura; St John's Research Institute, Division of Nutrition } \\
\text { Wells, Jonathan; UCL Institute of Child Health, Childhood Nutrition } \\
\text { Research Centre }\end{array}$ \\
\hline Keywords: & $\begin{array}{l}\text { moderate acute malnutrition, body composition, stable isotope, deuterium } \\
\text { dilution }\end{array}$ \\
\hline
\end{tabular}


Deuterium dilution technique for body composition assessment: resolving methodological issues in children with moderate acute malnutrition

Christian Fabiansen ${ }^{\mathrm{a}, \mathrm{b}, \mathrm{c}}$, Charles W. Yaméogo ${ }^{\mathrm{a}, \mathrm{d}, \mathrm{e}}$, Sarita Devi ${ }^{\mathrm{f}}$, Henrik Friis ${ }^{\mathrm{a}}$, Anura Kurpad ${ }^{\mathrm{f}}$, Jonathan Wells ${ }^{\mathrm{g}}$

${ }^{a}$ Department of Nutrition, Exercise and Sports, University of Copenhagen, Rolighedsvej 30, DK-1958 Frederiksberg C, Denmark

${ }^{b}$ Médecins Sans Frontières - Denmark, Dronningensgade 68, 3. 1420 Copenhagen, Denmark

${ }^{c}$ Alliance for International Medical Action, Route de l'Aéroport, Rue NG 96 BP: 12000 Résidence, Dakar, Sénégal

${ }^{d}$ Centre de Recherche en Sciences Biologiques, Alimentaires et Nutritionnelles, UFRSVT/Université de Ouagadougou, 03 BP:7131 Ouagadougou 03, Burkina Faso.

${ }^{e}$ Institut de Recherche en Sciences de la Santé, Ministère des Enseignements Supérieurs, de la Recherche Scientifique et de l'Innovation, 03 BP: 7192 Ouagadougou 03, Burkina Faso

${ }^{f}$ Division of Nutrition, St John's Research Institute, Opp. BDA Complex, Koramangala, Bangalore - 560 034, India

${ }^{g}$ Childhood Nutrition Research Centre, UCL Institute of Child Health, 30 Guilford Street, London WC1N 1EH, UK

Address for correspondence:

Christian Fabiansen, MD

Department of Nutrition, Exercise and Sports,

University of Copenhagen, Rolighedsvej 30,

DK-1958 Frederiksberg C, Denmark Phone

Email: chfa@nexs.ku.dk 
1

2

3

4

5

6

7

8

9

\begin{abstract}
Childhood malnutrition is highly prevalent and associated with high mortality risk. In observational and interventional studies among malnourished children body composition is increasingly recognised as a key outcome. The deuterium dilution technique has generated high-quality data on body composition in studies of infants and young children in several settings, but its feasibility and accuracy in children suffering from moderate acute malnutrition requires further study.

Prior to a large nutritional intervention trial among children with moderate acute malnutrition we conducted pilot work to develop and adapt the deuterium dilution technique. We refined procedures for administration of isotope doses and collection of saliva. Furthermore, we established that equilibration time in local context is 3 hours.
\end{abstract}

These findings and the resulting standard operating procedures are important to improve data quality when using the deuterium dilution technique in malnutrition studies in field conditions, and may encourage a wider use of isotopes techniques.

Keywords: Stable isotope, deuterium dilution, moderate acute malnutrition, body composition. 


\section{Introduction}

Childhood malnutrition continues to be highly prevalent and is associated with

high mortality risk [1]. Traditionally, outcomes in studies addressing malnutrition have been based on anthropometry i.e. weight, weight-for-height z-score (WHZ) or midupper-arm circumference (MUAC). These outcomes, however, do not discriminate between fat and lean mass. Lean mass is likely to mediate many of the beneficial functional outcomes, whereas fat is important as an energy substrate, and may play a role promoting immune function, but may also increase the long term risk of chronic diseases [2].

As yet, it is unclear how lean and fat mass might benefit survival in early life. Low levels of leptin, associated with fat mass, predict mortality in children with severeacute malnutrition (SAM) [3], but lean mass has also been proposed to promote survival $[4,5]$. Highly precise methods for the assessment of body composition such as airdisplacement plethysmography or dual-energy X-ray absorptiometry are used in research settings, but are impractical and expensive to use in larger field studies $[6,7]$. The deuterium dilution technique offers a logistically more feasible alternative in field studies by obtaining measurements of total body water (TBW) from which the two components of fat and lean mass can be derived. The use of the deuterium dilution technique has generated high-quality data on body composition in studies of infants and young children in several low- and middle-income country settings (Peru [8], Gambia [9], Ethiopia [10], Nepal [11], India [12]), and in larger trials of moderate acute malnutrition (MAM) prevention in countries such as Cambodia and Kenya [13].

We chose absolute lean mass increment measured using the deuterium dilution technique as the primary outcome in a large randomized trial (Treatfood) conducted in Burkina Faso among children aged 6-23 months and suffering from MAM (weight-for- 
45 height $\mathrm{z}$ score (WHZ) between -3 and -2 , and/or a measure of mid-upper arm

46 circumference (MUAC) between 115 and $124 \mathrm{~mm}$ ) [14].

47 In principle, measurement of TBW by isotopic methods is relatively simple in

48 most age groups, requiring only the collection of urine or saliva samples, before and

49 after a single dose of deuterium labelled water. In practice, several methodological

50 issues need to be addressed, particularly in younger age groups. We have previously

51 evaluated different methods of administering isotope doses to healthy breastfed babies

52 in a high-income setting, who may be unfamiliar with drinking water [15], but a wider

53 range of methodological issues may be challenging when applying the method to

54 children with MAM studied under difficult field conditions, such as in rural Africa.

55 In addition, low costs relative to isotope-ratio mass-spectrometry make Fourier

56 transform infrared spectroscopy (FTIR) an attractive analytical option for large trials.

57 However, FTIR requires saliva samples, but many previous isotope studies in infants

58 and young children used urine samples, and little is known of the feasibility of saliva

59 sampling in younger age groups, especially in challenging field conditions, such as hot

60 and arid environments.

61 Prior to our trial, we therefore conducted pilot work to adapt and develop the

62 deuterium dilution technique specifically for use in children with MAM and the local

63 Burkinabe setting, while also testing large-scale logistical feasibility. This paper

64 describes our efforts to (a) optimise the processes of saliva sampling and fluid

65 administration, (b) evaluate the effects on the analysis technique of adding of sugar to

66 the isotope dose to promote palatability, (c) minimise fractionation bias in collecting

67 saliva, (d) minimise evaporation through isotope dose spillage, (e) evaluate precision of

68 isotope abundance determination in aliquots taken at intervals from a single deuterium 
69 oxide stock solution and (f) to determine isotope equilibration time in children with

\section{MAM.}

71

72

73

74

\section{Methods}

The pilot study took place in Province du Passoré at Gonpomsom Health centre in the Northern region of Burkina Faso in January-February 2013. Characteristics of methods, participants and samples are described in the relevant sub-studies (a-f) below.

\subsection{Basic protocol and analytical technique}

From application of the deuterium dilution technique an estimation of TBW is obtained from which the two components of fat mass (FM) and fat free mass (FFM) can be derived. Calculation of TBW requires information on baseline level of isotopic abundance in the body water pool, the isotopic abundance of the dose solution, and post-dose levels of isotopic abundance in the body water pool.

\section{The basic protocol for body composition assessment therefore consists of four} different procedures. (1) Collection of a pre-dose saliva sample to establish the baseline level of deuterium oxide $\left({ }^{2} \mathrm{H}_{2} \mathrm{O}\right)$ in child. (2) Administration of a dose consisting of ${ }^{2} \mathrm{H}_{2} \mathrm{O}(99.8 \%$, Cambridge Isotope Laboratories Inc., Andover, USA), diluted with water, followed by an appropriate equilibration period. (3) Collection of a post-dose saliva sample. (4) Determination of isotope abundances in these samples by Fourier Transform Infrared Spectrometer (FTIR) (IRAffinity-1, Shimadzu, Kyoto, Japan) at St. John's Research Institute (Bangalore, India). This approach quantifies the relative concentrations of ${ }^{1} \mathrm{H}_{2} \mathrm{O}$ versus ${ }^{2} \mathrm{H}_{2} \mathrm{O}$ in fluid samples.

To calculate the deuterium dilution space $(\mathrm{N})$ the following equation is used [16]: 
$93 N=\left(T^{*} A / a\right) *[(E d-E t) /(E s-E p)]$

94

95 Where:

96 Tis the diluent (mass of tap water for dilution in lab + mass of dose diluted in lab) ( $g$ )

$97 \quad A$ is the mass of the dose ingested by child in field ( $g$ )

98 a is the mass of the dose that is further diluted in lab for FTIR analysis ( $g$ )

99 Ed is the isotopic abundance of the dose solution (ppm)

100 Et is the isotopic abundance of the tap water used to dilute the dose in lab (ppm)

101 Es is the isotopic abundance of the post-dose sample of saliva (ppm)

102 Ep is the isotopic abundance of the pre-dose sample of saliva (ppm)

103

104 Subsequently the two-component body composition can be derived as:

105

$106 T B W(g)=N / 1.044$ (adjusted for exchange of hydrogen atoms in tissues $[17,18]$ )

$107 \quad F F M(g)=$ TBW/hydration factor $[19,20]$

$108 F M(g)=$ Body weight $-F F M$

109

110 In our study, the aim was not to calculate body composition using this method, but

111 rather to optimise several discrete components of the protocol, by resolving challenges

112 expected in children with moderate acute malnutrition. These specific issues are

113 described below.

URL: http://mc.manuscriptcentral.com/gieh Email: editoriehs@ufz.de 


\section{$114 \quad 2.2$ Pilot studies}

115 Sub-study (a): feasibility of saliva sampling and fluid administration

116 The first issue concerns questions of feasibility for the field part of the basic

117 protocol in children with MAM: how should the saliva samples be collected to obtain

118 adequate volumes, and how should the dose be administered to get an accurately

119 quantified measurement of dose ingested by infant. This first sub-study involved 23

120 children 6-30 months old, consisting of well-nourished children ( $\mathrm{n}=12)$; MAM $(\mathrm{n}=8)$;

121 and severe acute malnutrition (SAM) $(n=3)$.

122

123 Saliva sampling

124 Our success criterion for saliva collection was a target volume of a minimum of

$1250.5 \mathrm{ml}$. In preliminary work, we tested viability of passive collection by a "cotton ball

126 method" as recently applied in field setting, which involves putting a cotton wool ball

127 with a string attached in the mouth of the child and wait until it is wet with saliva [13].

128 Subsequently active collection by lavage of the oral cavity with a "cotton stick method"

129 was developed by applying extra layers of cotton to regular cotton sticks. Possible

130 fractionation bias in saliva collection was tested in sub-study (c).

132 Fluid administration

133 Our success criterion for fluid (dose) administration was finding an approach

134 that led to high acceptability whilst enabling precise measurements of the volume

135 ingested. For ethical considerations, neither nasogastric tubes nor administration by

136 intravenous route was considered. Oral fluid administration using water was tested

137 using (1) disposable syringes, (2) syringes with a short butterfly catheter placed in 
138 mouth, (3) various local cups and (4) different types of baby bottles with teat holes in

139 various sizes. We also evaluated whether the addition (dilution) to the dose with a well-

140 known local drink, Bissap (sugary and containing hibiscus), would improve palatability

141 (sub-study (b)). The effect of local climatic conditions on evaporation of spillage was

142 tested separately in sub-study (d).

143 Sub-study (b): the effects of adding of sugar to the dose solution

144 Our success criterion when evaluating the addition of Bissap to the dose solution

145 was that analytic accuracy was maintained in the FTIR analysis. Bissap contains sugar

146 and to our knowledge no data is available on the effect of sugar on accuracy of the ${ }^{2} \mathrm{H}_{2} \mathrm{O}$

147 abundance determination by FTIR. Diluted ${ }^{2} \mathrm{H}_{2} \mathrm{O}(0.1 \mathrm{~g} / \mathrm{ml})$ with and without sugar

148 (sucrose at about 2 teaspoons of sugar in $100 \mathrm{ml}$ ) was analysed by FTIR, to identify the

149 possible interference of sugar.

150 Sub-study (c): fractionation bias in collecting saliva

151 This sub-study was undertaken in seven adult volunteers. The objective was to

152 evaluate the effect on isotopic abundance of saliva sampled with an open mouth versus

153 a closed mouth. It is unknown whether collecting saliva from an open mouth might

154 cause isotopic fractionation, whereby heavy and light isotopes evaporate at different

155 rates. This would alter the relative isotopic abundance of the sample and yield

156 inaccurate data on body composition.

157 Ambient temperature was $\sim 38^{\circ} \mathrm{C}[21]$ during the experiments. Undiluted ${ }^{2} \mathrm{H}_{2} \mathrm{O}$,

158 administered in proportion to body weight was ingested $\left(0.4 \mathrm{~g}^{2} \mathrm{H}_{2} \mathrm{O}\right.$ per $\mathrm{kg}$ body

159 weight). In the four-hour waiting period individuals minimised physical activity. No

160 drinking or eating $30 \mathrm{~min}$. before saliva sampling was permitted, nor rinsing of the

161 mouth at any time. Saliva was collected using the cotton stick method while the 
162 participant's mouth was kept closed. After 3 minutes, saliva collection was repeated

163 with an open mouth while the required volume of saliva was collected. The aim was to

164 obtain $1 \mathrm{ml}$ of saliva. If more than $0.5 \mathrm{ml}$ saliva was obtained after the use of four

165 cotton sticks the experiment was terminated. If $<0.5 \mathrm{ml}$ saliva additional cotton-stick

166 sampling would be performed.

Sub-study (d): evaporation through dose spillage

169 When administering ${ }^{2} \mathrm{H}_{2} \mathrm{O}$ to a child, small amounts of the dose may not be

170 consumed, and may be spilled. If these spills are not recovered, the volume of dose

171 administered would be over-estimated, leading eventually to an over-estimation of

172 TBW by the same percentage magnitude. It is therefore necessary to collect spillages,

173 for example on pre-weighed pieces of gauze (tissue), so that the mass of spillage can be

174 quantified. In a hot, dry setting, however, these spillages may rapidly evaporate.

175 Evaporation was tested in four small experiments with 3 pieces of gauze tested in each.

176 Gauzes were prepared with $\sim 1$ g diluted ${ }^{2} \mathrm{H}_{2} \mathrm{O}$, placed in sealed plastic bags and

177 weighed with $0.01 \mathrm{~g}$ precision (Adam equipment: model CQT 202, United Kingdom).

178 On opening the bags, half the pieces of gauze were curled up and pressed against the

179 lower lip of an adult study participant to mimic "normal collection" of spillage on the

180 face for three or seven minutes. The other half was left to "free-dry" in the air for three

181 to seven minutes. After exposure, each piece of gauze was transferred back to its bag

182 and reweighed. 
183 Sub-study (e): precision of dosing isotope abundance determination from stock

184 solution

185 Calculation of TBW requires precise knowledge of both the mass of the dose

186 and the abundance of isotope in the dose. A Diluted Deuterium oxide Stock (DDS) is

187 prepared by mixing commercially available ${ }^{2} \mathrm{H}_{2} \mathrm{O}$ and water. As successive doses are

188 removed from the stock solution, its isotopic content may change, such that the doses do

189 not share a common isotopic abundance. The objective of this study was to test if

190 isotope abundance of DDS samples would be similar when measured repeatedly on

191 different days. We determined the isotopic abundance of several DDS samples (in each

192 case sampled from the mid-bottle of a DDS solution) taken from two different DDS

193 solutions (both $\sim 40 \%$ solution $\sim 400 \mathrm{~g}^{2} \mathrm{H}_{2} \mathrm{O}$ and $\sim 600 \mathrm{~g} \mathrm{H}_{2} \mathrm{O}$ ). The first DDS solution

194 was sampled on days 1,2,5,6 and 7. The second DDS solution was sampled on days 1, 2

195 and 5.

196

197

Sub-study (f): Equilibration time

198 The objective of this sub-study was to establish the ${ }^{2} \mathrm{H}_{2} \mathrm{O}$ equilibration time in

199 saliva for children with MAM. The experimental overview is seen in figure $\mathbf{1}$.

200 Following collection of baseline saliva, $10 \mathrm{ml}$ of diluted ${ }^{2} \mathrm{H}_{2} \mathrm{O}(\sim 40 \%$ concentration, $\sim 4$

201 g D2O) was administered as a fixed dose. Saliva samples were collected at hourly

202 intervals (3,4 and 5 hours) in a sample of 42 children (well-nourished recovering from

203 MAM=13; MAM n=22; SAM=7) aged 7-30 months. Since our aim was to determine

204 equilibration time, we included in our analysis children who spilled some of the dose,

205 because while this would negate accurate calculation of body water, it would not

206 prevent assessment of equilibration time.

URL: http://mc.manuscriptcentral.com/gieh Email: editoriehs@ufz.de 
207

208

209

210

211

212

213

214

215

216

217

218

219

220

221

222

223

224

225

226

227

228

229

\subsection{Statistics}

Data were double entered in Epidata 3.1 (Odense, Denmark). Descriptive summary measures (percentage, mean $+/$ - SEM) were used to analyze the data. No

formal statistical significance testing was carried out due to limitations in sample size.

The statistical software package Stata v12 (StataCorp, College station, Texas, USA) was used.

\subsection{Ethics}

This study was approved as part of a larger trial by the Ethics Committee for Health Research in Burkina Faso (2012-8-059) and consultative approval was obtained from the Danish National Committee on Biomedical Research Ethics (1208204).

\section{Results}

Sub-study (a): feasibility of saliva sampling and fluid administration

The "cotton ball method" applied in a recent trial in Cambodia, allowing a child to suck on a cotton ball with a tied-on thread hanging out the mouth hold by the investigator to prevent swallowing, failed in our setting. Children would generally not close their mouths with the cotton-ball inside and too little saliva was collected. On the other hand, the "cotton-stick method", by which we collected saliva by systematically sweeping the oral cavity, proved effective in collecting our minimum target volume of $0.5 \mathrm{ml}$.

When administrating fluid directly from a syringe to a child, initially, low acceptability and high levels of spillage were encountered. Consequently, a number of alternative techniques were investigated: a number of local cups were found to lead to excessive spillage both when applied by investigators and mothers. In healthy children 
230 there was a tendency of better acceptance when drinking fluid from a baby bottle. But in

231 children with MAM there was generally little will to suck from the baby bottle. Making

232 sucking easier by increasing the size of the hole in the teat led to excessive spillage. In

233 healthy children a well-known local drink, Bissap (sugary and containing hibiscus), was

234 well accepted when tested as dilution. Bissap being red in colour also made it possible

235 to discriminate between spillage from pure saliva and spillage from diluted ${ }^{2} \mathrm{H}_{2} \mathrm{O}$.

236 However, when tested in children with MAM, Bissap was not better accepted than

237 water. We identified no better way to administrate fluid than by disposable syringes.

\section{Sub-study (b): the effects of adding of sugar to the dose solution}

239

240

241

242

243

244

245

246

247

248

249

250

251

252

253
Testing the addition of sucrose, in the laboratory setting, led to a large

interfering peak which altered the appearance of the O-D stretch, and affected the calculation of ${ }^{2} \mathrm{H}_{2} \mathrm{O}$ abundance. A known standard of 1184 ppm of ${ }^{2} \mathrm{H}_{2} \mathrm{O}$ mixed with sucrose as a $10 \%$ solution resulted in a higher observed isotope abundance of $1560 \pm 1$ ppm.

Sub-study (c): fractionation bias in collecting saliva

We show the differences in the adult post dose saliva (Es) isotopic abundances collected with mouth closed and mouth open in Table 1. To estimate consequences for these differences in post-dose isotopic abundances relevant to our paediatric population we calculated dilution space, $\mathrm{N}$, with hypothetical values for TA/a=5000, $\mathrm{Ed}-\mathrm{Et}=1000$, $\mathrm{Ep}=96$. These calculated differences in dilution space were considerable, ranging from 4 to $7 \%$. 
254

255

256

257

258

259

260

261

262

263

264

265

266

267

268

269

270

271

272

273

274

275

276

277

Sub-study (d): evaporation through dose spillage

There was a $31 \%$ (SEM 3 ) evaporation of diluted ${ }^{2} \mathrm{H}_{2} \mathrm{O}$ from gauzes across experimental conditions in this sub-study. Details on results of the experiments are seen in Table 2.

Sub-study (e): precision of dosing isotope abundance determination from stock solution

As seen in Table 3 we found up to $8 \%$ difference in isotope abundance determination in samples from same DDS solution measured on different occasions.

\section{Sub-study (f): Equilibration time}

The children had an average weight of $7.3 \mathrm{~kg}$ (SEM 0.2) (range 4.81-9.8).

Baseline saliva was successfully obtained in 39 of 42 children (93\%) with a mean saliva volume of $1 \mathrm{ml}$ (SEM 0.06). Three children failed to produce baseline saliva due to crying and dry mouths and were taken out of the study. In two children the dose was not given due to crying and these children were taken out of the study. Samples from one child were lost.

In the 36 remaining children all post-dose saliva samples were successfully collected. Equilibrium was reached at three hours as seen in Figure 2 as abundance of deuterium in saliva (Panel A) or calculations of TBW (Panel B). In the vast majority of children there was a clear pattern. From three hours onwards, subsequent total body waters were either essentially static (defined a change of $<0.1 \mathrm{~kg} \mathrm{TBW}$ ) or rising slightly. All of these subjects indicated equilibration of isotope by three hours. In four children a pattern was found with a rise in TBW (fall in isotope abundance) from three to four hours followed by a rise from four to five hours. We suspect these findings to be artefacts possibly being caused by a large drink between three and four hours. One child 
278 showed three very different values, the highest value at 4 hours, and we suspect an

279 irregularity with drinking (e.g. in the period prior to 3 hours), or saliva sampling (e.g.

280 evaporation/fractionation at 1 or more time points) or both.

\section{4. Discussion}

282 Prior to a randomized trial we conducted a pilot to adapt and develop the

283 deuterium dilution technique specifically for use in children with MAM and a hot

284 climate and rural setting. Our findings and considerations may be of wider use for field

285 studies in undernutrition considering body composition as an outcome.

286

287

288

289

290

291

292

293

294

295

296

297

298

299

300

\subsection{Saliva collection}

We developed a cotton-stick method that ensured a high success rate of $>90 \%$ for saliva collection. Likewise, we established that isotope abundances of post-dose saliva samples were determined differently if collected with an open mouth compared to a closed mouth, possibly related to fractionation, and we recommend that saliva is collected while the mouth of the child is gently kept closed. We decided for the trial to drape the saliva collection environment with a cloth, to protect the process from direct sunlight and also to minimise risk of fractionation. At the time of our pilot the FTIR equipment used required $\sim 0.5 \mathrm{ml}$ per analysis, hence $\sim 1 \mathrm{ml}$ per duplicate isotope abundance determination. Newer FTIR systems allow duplicate analysis of as little as 60 microliters which will ease the collection of sample material for future trials. To minimise risk of contamination of saliva samples, we physically separated the location for dosing and saliva collection. In addition, a 30 minutes fasting period saliva before sampling was requested including breastfeeding. 
301

302

303

304

305

306

307

308

309

310

311

312

313

314

315

316

317

\subsection{Dose and administration}

When running a large trial, it is important to simulate what the highest and lowest isotope abundance would be from putting the same dose into a small and a large child. If the child was very big, the post-dose enrichment would be low; if the child was small, the dose would be high. It depends what range of isotope abundances the FTIR lab are able to cover.

We used diluted ${ }^{2} \mathrm{H}_{2} \mathrm{O}$ for dosing, as undiluted ${ }^{2} \mathrm{H}_{2} \mathrm{O}$ may lead to inaccuracy of estimation of dose ingested by child. ${ }^{2} \mathrm{H}_{2} \mathrm{O}$ is enriched relative to water vapor in the air and will fractionate rapidly. The risk is that not all the dose swallowed and evaporates off the surface of the mouth and throat. With a dose of $5 \mathrm{~g}$ isotope, a loss of $0.05 \mathrm{~g}$ in this way will result in a $1 \%$ dosing error, i.e. a $1 \%$ body water error. In the same way, scales weighing accurate to at least $0.01 \mathrm{~g}$ are necessary to minimize error on the calculated mass of dose administered.

By diluting the dose with potable water, the relative error of evaporation will be reduced. The magnitude of dilution of the dose is influenced by both biological and practical logistical considerations. To cover all weight ranges in our trial and to make logistics as easy as possible for the trial, all children received $5 \mathrm{~g}^{2} \mathrm{H}_{2} \mathrm{O}$ in about $10 \mathrm{~mL}$ DDS, meaning that the total dose to be consumed was $\sim 10 \mathrm{~mL}$.

When running a large trial it is tempting to reduce the workload by determining isotope abundance in the DDS solutions and use this value for all children having received an aliquot from this solution. However, in this pilot we established substantial variability in samples from same DDS aliquoted on different time points. Subsequently, we decided for our main trial to analyse isotopic abundance in every individual dose given a so-called individual study dose (ISD).

We tested various techniques for dosing, and ended up with the conventional use of disposables syringes. Likewise, we had to abandon the idea of adding a local flavour 
327 to the dose as the sugar content in the local drink identified would have interfered with

328 isotope abundance analysis in FTIR analysis. For studies analysing samples on mass

329 spectrometry the addition of sugar would still be an option. However, from a logistical

330 point of view using disposable material and plain water as diluent makes a large study

331 more feasible. We established that in the local setting evaporation takes place extremely

332 fast with the risk of overestimation of dose in child. For our trial we made procedures to

333 minimize time dose was exposed to environment and to instantly place gauze with

334 spillage into airtight containers.

335 We established that equilibration time in saliva in local context is 3 hours,

336 just a few children diverted from this pattern which we consider was probably

337 related to the ingestion of large drinks during the equilibration period. Previous

338 work in younger age groups has been conducted on healthy subjects in high

339 income settings. Most work on infants has used a "back extrapolations" method

340 [16] to calculate body water. This uses repeat post-dose urine samples across

341 several days, since body water was typically calculated as part of the doubly

342 labelled water method for estimation of energy expenditure. Other studies of

343 infants, children and adults suggest that isotopic equilibration typically occurs in

344 saliva within three hours [22,23], however a longer period may be required for

345 those overweight. No information is available on the time required for

346 equilibration in undernourished children.

347 Furthermore, as some children during dosing would spit in a manner or degree

348 that could not be collected by gauze, we decided for our trial to include estimation of

349 dose loss if administration was not perfect. Also to avoid the risk of children vomiting

350 after the dosing we imposed an observation period following dose administration. 
351 During our trial we improved the psycho-social environment by using only experienced

352 local staff and creating a playful/calm atmosphere.

353

354

355

356

357

358

359

360

361

362

363

364

365

366

367

368

369

370

371

372 373
The experiences from our pilot study let to development of standard operational procedures for management of the deuterium dilution techniques in our trial that can be found as online supplemental material. Online supplemental material 1: Laboratory Deuterium oxide dilution, Sampling and Aliquoting. Online supplemental material 2:

Dose administration in field and Online supplemental material 3: Field data collection sheet.

A limitation of our study is that we did not propagate our raw isotopic data to body water values and hence body composition, which would potentially have allowed us to assess the overall accuracy of the deuterium technique relative to a reference body composition method (eg air-displacement plethysmography). We did not have access to any such reference method in this field setting. Such a validation study would be a valuable future aim. Nevertheless our work reported here has clarified how to optimise the protocol for collecting isotopic data in children with moderate acute malnutrition.

\section{Conclusion}

We established how to collect saliva and dose diluted ${ }^{2} \mathrm{H}_{2} \mathrm{O}$ in a local Burkinabe setting prior to a large intervention study in children with MAM. Our pilot findings and standard operating procedures developed for the main trial may be of wider use for groups considering using the deuterium dilution technique in malnutrition studies in field conditions. However, we encourage that a local pilot is always undertaken prior to the application of this method. 
1

2

3

4

5

6

7

8

9

10

11

12

13

14

15

16

17

18

19

20

21

22

23

24

25

26

27

28

29

30

31

32

33

34

35

36

37

38

39

40

41

42

43

44

45

46

47

48

49

50

51

52

53

54

55

56

57

58

59

60

\section{Acknowledgements \\ 375 We would like to thank Ann-Sophie Iuel-Brockdorff and Bernardette Cichon for their \\ 376 invaluable contributions in setting up and running this study.}




\section{References:}

1. Black RE, Victora CG, Walker SP, Bhutta ZA, Christian P, de Onis M, Ezzati M, Grantham-McGregor S, Katz J, Martorell R. Maternal and child undernutrition and overweight in low-income and middle-income countries. The Lancet. 2013;382:427-451.

2. Friis H, Michaelsen KF, Wells JC. Choice of design and outcomes in trials among children with moderate acute malnutrition. 2015.

3. Bartz S, Mody A, Hornik C, Bain J, Muehlbauer M, Kiyimba T, Kiboneka E, Stevens R, Bartlett J, St Peter JV, Newgard CB, Freemark M. Severe Acute Malnutrition in Childhood: Hormonal and Metabolic Status at Presentation, Response to Treatment, and Predictors of Mortality. J. Clin. Endocrinol. Metab. 2014 Jun;99:2128-2137.

4. Sauerwein HP, Serlie MJ. Optimal nutrition and its potential effect on survival in critically ill patients. Neth. J. Med. 2010 Mar;68:119-122.

5. Briend A, Khara T, Dolan C. Wasting and stunting — similarities and differences: policy and programmatic implications. Food Nutr. Bull. 2015;36:15S - 23S.

6. Snijder MB, Dam R van, Visser M, Seidell JC. What aspects of body fat are particularly hazardous and how do we measure them? Int. J. Epidemiol. 2006 Jan;35:83-92.

7. Wells JCK, Fewtrell MS. Measuring body composition. Arch. Dis. Child. 2006 Jan;91:612-617.

8. Fjeld CR, Freundt-Thurne J, Schoeller DA. Total Body Water Measured by 180 Dilution and Bioelectrical Impedance in Well and Malnourished Children. Pediatr. Res. 1990 Jan;27:98-102.

9. Wells JCK, Hawton K, Darch T, Lunn PG. Body composition by $2 \mathrm{H}$ dilution in Gambian infants: comparison with UK infants and evaluation of simple prediction methods. Br. J. Nutr. 2009 Dec;102:1776.

10. Andersen GS, Girma T, Wells JC, Kæstel P, Leventi M, Hother A-L, Michaelsen $\mathrm{KF}$, Friis H. Body composition from birth to 6 mo of age in Ethiopian infants: reference data obtained by air-displacement plethysmography. Am. J. Clin. Nutr. 2013 Oct;98:885-894.

11. Devakumar D, Chaube SS, Wells JCK, Saville NM, Ayres JG, Manandhar DS, Costello A, Osrin D. Effect of antenatal multiple micronutrient supplementation on anthropometry and blood pressure in mid-childhood in Nepal: follow-up of a double-blind randomised controlled trial. Lancet Glob. Health. 2014 Nov;2:e654e663. 
12. Jain V, Kurpad AV, Kumar B, Devi S, Sreenivas V, Paul VK. Body composition of term healthy Indian newborns. Eur. J. Clin. Nutr. 2015 Sep; .

13. Skau JK, Touch B, Chhoun C, Chea M, Unni US, Makurat J, Filteau S, Wieringa FT, Dijkhuizen MA, Ritz C, Wells JC, Berger J, Friis H, Michaelsen KF, Roos N. Effects of animal source food and micronutrient fortification in complementary food products on body composition, iron status, and linear growth: a randomized trial in Cambodia. Am. J. Clin. Nutr. 2015 Jan;101:742-751.

14. Fabiansen C, Phelan KP, Cichon B, Ritz C, Briend A, Michaelsen KF, Friis H, Shepherd S. Short children with a low midupper arm circumference respond to food supplementation: an observational study from Burkina Faso,. Am. J. Clin. Nutr. 2016 Feb;103:415-421.

15. Nielsen SB, Wells JCK, Slater C, Fewtrell MS, Reilly JJ. Administering labelled water to exclusively breast-fed infants in studies involving stable isotope dilution techniques. Isotopes Environ. Health Stud. 2011 Mar;47:18-25.

16. Davies PS, Wells JC. Calculation of total body water in infancy. Eur. J. Clin. Nutr. 1994 Jul;48:490-495.

17. Racette SB, Schoeller DA, Luke AH, Shay K, Hnilicka J, Kushner RF. Relative dilution spaces of $2 \mathrm{H}$-and 18O-labeled water in humans. Am. J. Physiol.Endocrinol. Metab. 1994;267:E585-E590.

18. Wells JCK, Ritz P, Davies PSW, Coward WA. Factors Affecting the $2 \mathrm{H}$ to $18 \mathrm{O}$ Dilution Space Ratio in Infants. Pediatr. Res. 1998 Apr;43:467-471.

19. Fomon SJ, Haschke F, Ziegler EE, Nelson SE. Body composition of reference children from birth to age 10 years. Am. J. Clin. Nutr. 1982 Jan;35:1169-1175.

20. Lohman T.G. "Estimating body composition in children and the elderly", Advances in Body Composition Assessment (Current Issues in Exercise Science, Monograph 3) (LOHMAN, T.G., Ed.), Human Kinetics, Champaign, IL (1992) 65-77.

21. Samson T. Météo à Ouahigouya en février 2013 [Internet]. Hist. Météo. [cited 2016 Mar 20]. Available from: http://www.historique-meteo.net/afrique/burkinafaso/ouahigouya/2013/02/.

22. Schoeller DA, Dietz W, Santen E van, Klein PD. Validation of saliva sampling for total body water determination by H2 18 O dilution. Am. J. Clin. Nutr. 1982 Jan;35:591-594.

23. Traver LÂM, Martinez FE, Ferriolli E, Marchini JS, Monteiro JP, Pfrimer K, Sanchez APM, de Oliveira T, Ducatti C, Camelo Jr JS. Deuterium equilibrium time in saliva of newborn infants. J. Pediatr. Gastroenterol. Nutr. 2009;48:471474. 
Table 1: The effect of closed vs open mouth on post-dose saliva enrichment in 7 adults

\begin{tabular}{cccccccccc} 
ID & Es1 & Es2 & $\Delta$ Es & Es1-Ep & Es2-Ep & $N 1$ & $N 2$ & $\Delta N$ & $\% \Delta N$ \\
\hline 1 & 583 & 572 & -11 & 487 & 476 & 10276 & 10508 & 232 & 2.3 \\
2 & 586 & 581 & -5 & 490 & 485 & 10200 & 10305 & 105 & 1.0 \\
3 & 652 & 615 & -38 & 556 & 519 & 8987 & 9641 & 655 & 7.3 \\
4 & 738 & 745 & 7 & 642 & 649 & 7792 & 7709 & -83 & -1.1 \\
5 & 555 & 574 & 19 & 459 & 478 & 10897 & 10453 & -443 & -4.1 \\
6 & 802 & 796 & -6 & 706 & 700 & 7080 & 7143 & 63 & 0.9 \\
7 & 730 & 724 & -7 & 634 & 628 & 7880 & 7967 & 87 & 1.1 \\
\hline
\end{tabular}

Es1 is isotope abundance of saliva collected with mouth closed. Es2 is isotope abundance of saliva collected with open mouth. To calculate dilution space $\mathrm{N}$ hypothetical values were used for $\mathrm{TA} / \mathrm{a}=5000, \mathrm{Ed}-\mathrm{Et}=1000, \mathrm{Ep}=96$ (not shown in table) 
Table 2: Effect of evaporation of spillage

\begin{tabular}{lcc} 
& Experiments & $\%$ weight (SEM) \\
\cline { 2 - 2 } a. Gauze touching skin, 3 min & $25(8)$ \\
b. Gauze touching skin, 7 min & $36(3)$ \\
c. & Loose gauze, 3 min & $22(2)$ \\
d. & Loose gauze, 7 min & $39(3)$ \\
\hline
\end{tabular}

Percentage weight loss of $\sim 1 \mathrm{~g}$ of diluted ${ }^{2} \mathrm{H}_{2} \mathrm{O}$. Determined in triplicate measurements in each of a-d 
Table 3: Accuracy in dosing abundance determination from diluted deuterium oxide stock solution

\begin{tabular}{cccccccccc} 
DDS \# & Day \# & A & twdil (g) & a (g) & Ed & Es-Ep & TA/a & $\mathbf{N}$ & $\% \mathbf{~ N}$ \\
\hline 1 & 1 & 10 & 49.9 & 0.106 & 816.3 & 1000 & 4699 & 5756.3 & - \\
1 & 2 & 10 & 49.4 & 0.101 & 794.5 & 1000 & 4903 & 6171.3 & 7.2 \\
1 & 5 & 10 & 49.5 & 0.103 & 820.6 & 1000 & 4825 & 5880.2 & 2.2 \\
1 & 6 & 10 & 49.2 & 0.100 & 793.9 & 1000 & 4922 & 6200.0 & 7.7 \\
1 & 7 & 10 & 49.2 & 0.104 & 829.3 & 1000 & 4754 & 5732.8 & -0.4 \\
2 & 1 & 10 & 49.1 & 0.100 & 799.7 & 1000 & 4906 & 6135.4 & - \\
2 & 2 & 10 & 49.3 & 0.102 & 804.9 & 1000 & 4834 & 6004.8 & -2.1 \\
2 & 5 & 10 & 48.9 & 0.103 & 820.7 & 1000 & 4771 & 5813.7 & -5.2 \\
\hline
\end{tabular}

$D D S \#$ indicates which of two diluted deuterium oxide stocks that was sampled. Day indicates day of sampling. Twdil is the mass of tap water used to analyse the DDS while $\mathrm{a}$ is the mass of DDS used to analyse isotope abundance. Ed is the determined dose abundance, while A, Es-Ep, TA/a are hypothetical values to calculate the dilution space in a child similar to our study population. 
Figure 1

Experimental overview to establish equilibration time sub-study (f)

Figure 2

Panel A: Deuterium oxide abundance of post dose saliva. Every line indicates a child that has had isotope abundance in saliva determined at 3, 4 and 5 hrs post dosage. Panel B: Calculated total body waters. 


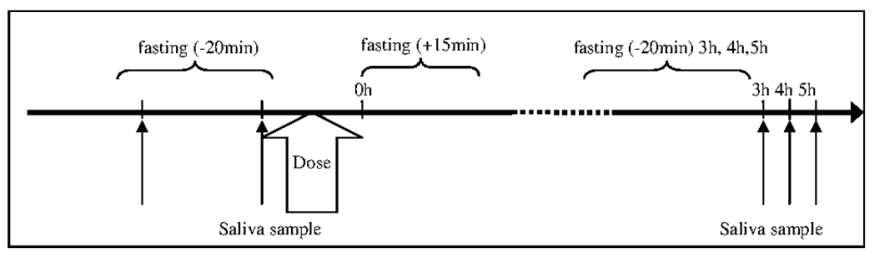

Experimental overview to establish equilibration time sub-study ( $f$ ) Experimental overview to estab $209 \times 297 \mathrm{~mm}(150 \times 150 \mathrm{DPI})$ 


\section{Panel A}

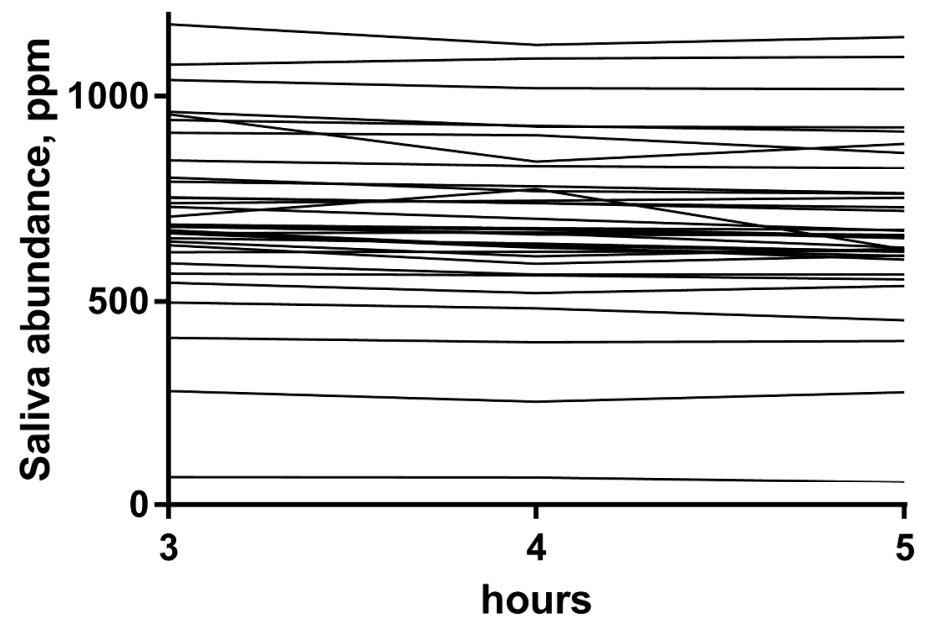

Panel B

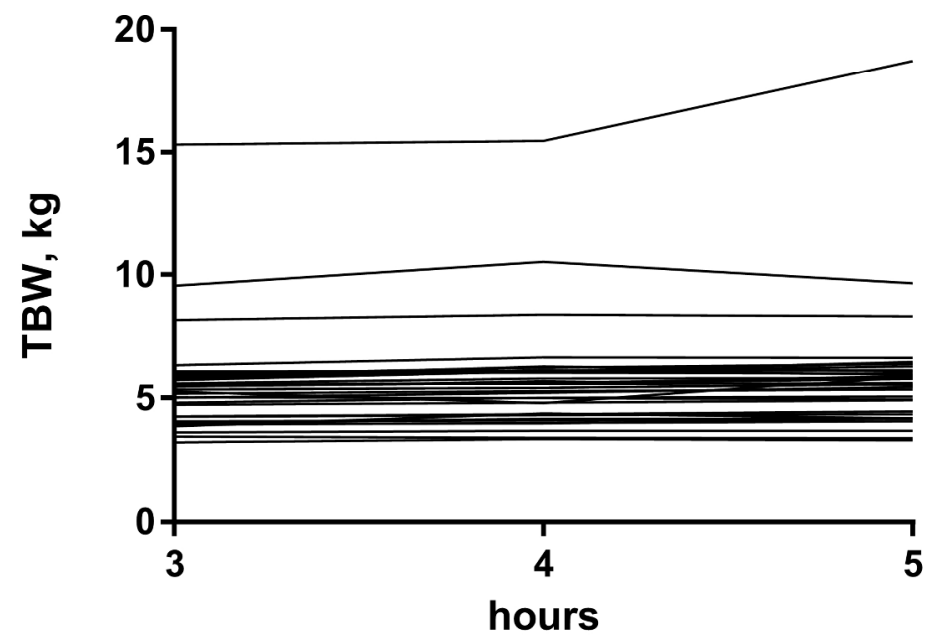

Figure 2

Panel A: Deuterium oxide abundance of post dose saliva. Every line indicates a child that has had abundance in saliva determined at 3,4 and 5 hrs post dosage. Panel B: Calculated total body waters.

$$
189 \times 271 \mathrm{~mm}(300 \times 300 \mathrm{DPI})
$$


ONLINE SUPPLEMENTAL MATERIAL 1

\section{Laboratory Deuterium oxide dilution, Sampling and Aliquoting}

\section{Preparation of DDS-batch}

A Diluted Deuterium oxide Stock (DDS) is prepared by mixing bottled-water (brand: Lafi) and 99.8\% D2O (brand: Cambridge Isotope). Mix DDS in a clean $1 \mathrm{~L}$ borosilicate bottle with a PTFE facing disc screw cap (mixing-bottle). Weigh on an electronic scale (range: 0-2 kg (0.1 g)). Keep lids on bottles during weighing to diminish evaporation.

a) Calibrate weight. Check against a standard object.

b) Tare bottle + lid (to $0.1 \mathrm{~g}$ ).

c) Dispense $\sim 450 \mathrm{~mL} 99.8 \% \mathrm{D} 2 \mathrm{O}$ to mixing-bottle using a glass cylinder.

d) Weigh D2O in the mixing-bottle ( $\sim 500 \mathrm{~g})$ and record exact weight in the DDS-log

e) Add $\sim 500 \mathrm{~mL}$ of bottled-water to the mixing bottle using a glass cylinder.

f) Weigh what is now a new DDS ( $\sim 1000 \mathrm{~g})$ and record exact weight in the DDS-log.

g) Mix DDS thoroughly by systematically turning mixing-bottle upside down 15 times before sampling and aliquoting.

Every new DDS is assigned a unique DDS-code: T-DDS-\#\#. Where \#\# is a new consecutive number.

a) When dispensing with new pipette tip DDS must be drawn back and forth 5 times to saturate the plastic pipette tip with $\mathrm{D} 2 \mathrm{O}$.

b) For every new DDS collect a $\sim 2 \mathrm{ml}$ sample (from the middle of the mixing-bottle) in a cryotube with O-ring. Label with $T$ - $D D S$-\#\# and store at $-20^{\circ}$.

\begin{tabular}{|l|c|c|c|c|}
\hline Data to register in the physical DDS-log book & Date & T-DDS-\#\# & Weight & Weight \\
and electronically & & & D2O & DDS \\
\hline
\end{tabular}

\section{Preparation of Dose-Bottles}

$12 \mathrm{ml}$ DDS is out-portioned in a Dose-Bottle $(10 \mathrm{ml}=$ Individual Study Dose (ISD) will be administered to study participant; the additional $2 \mathrm{ml}=$ ISD-sample will establish the exact abundance of D2O in Dose-Bottle). One DDS is enough for $\sim 78$ Dose-bottles.

c) Dispense exactly $12 \mathrm{ml}$ DDS by using a pipette into a Dose-Bottle that is immediately closed.

d) Add label on the Dose-Bottle with: T-DDS-\#\#.

e) After Aliqouting 10 Dose-Bottles mix remaining DDS thoroughly by systematically turning mixing-bottle upside down 15 times.

f) Place Dose-Bottle in fridge $\left(4^{\circ} \mathrm{C}\right)$ in until field usage.

\section{$\underline{\text { Logistics }}$}


DDS is mixed and Dose-bottles prepared according to field needs and kept in fridge $\left(4^{\circ} \mathrm{C}\right) .1 \mathrm{DDS}$ contains a volume for $\sim 78$ Dose-Bottles (if field needs are small freeze half the Dose-Bottles). Every morning Dose-bottles are transported from lab to field-sites in a cold bag. Unused Dosebottles are returned to fridge in lab every evening and a dot is added to the label indicating a "dayin-the-field". Dose-Bottle with most dots should be used first in field. However, Dose-Bottles with five dots must be thrown out.

\section{Background for choosing $5 \mathrm{~g} \mathrm{D20:}$}

In TreatFood children aged 6-23 months with MAM are included. Intervention is for 3 months. An ISD is administered at $\mathrm{t}=0$ and $\mathrm{t}=3$ months. Gross Estimation of weight range: $5.1-12.5 \mathrm{~kg}(6$ months-old- girls -3SD/ 26 months-old-boy median (based on weight-for-height WHO standards)).

The proportion of water in the body varies in relation to fatness. In thin children, lean mass can be $>90 \%$ of the weight and if hydration of lean tissue were $78 \%$, around $70 \%$ of weight could be water - possibly even more as malnutrition can lead to water retention. With $5 \mathrm{~g}$ of D20 and an hydration of body mass of $70 \%$ the estimated range of enrichment according to weight range will be $5 \mathrm{~g} \mathrm{D} 20 /($ weight $* .7)=\sim 570-1400 \mathrm{ppm}$.

\section{Background for DDS mixing D20 dilution:}

Calculations made on the assumption that temperature is $25 \mathrm{C}^{\circ}$

Density D2O: $1.105 \mathrm{~g} / \mathrm{mL}$

Density H2O: $0.997 \mathrm{~g} / \mathrm{mL}$

Characteristics of one DDS:

Volume: $950 \mathrm{ml}(450 \mathrm{ml} \mathrm{D} 2 \mathrm{O}+500 \mathrm{ml} \mathrm{H} 2 \mathrm{O})$

Weight: 995 gr (497 gr D2O + 498 gr H2O)

Weight proportion D2O/DDS $\sim 0,5$

$1 \mathrm{~mL}$ of DDS weighs: $\sim 1.048 \mathrm{gr}$

$1 \mathrm{~mL}$ of DDS contains : 0.523 gr D2O (1.048 gr * 0.5)

5 gr D2O in: 10 mL DDS or Precisely 9.56 ml DDS (5 gr D2O/0.523 gr D2O/ml DDS) 


\section{ONLINE SUPPLEMENTAL MATERIAL 2}

\section{$\underline{\text { Dose administration in field }}$}

A successful dose administration is: When the precise weight of D2O swallowed by child is known and when $0.5-1 \mathrm{ml}$ of saliva has been collected before and after dosing.

The method takes time, precision and patience! Procedures must never be rushed and a child-friendly environment must at all times be maintained. Activities are separated in three different locations in field: Observation (OBS), Saliva sampling (SAL) and dosing (DOSE). All information must be meticulously recorded according to the Deuterium Data Collection Sheet of individual children and in a general Deuterium Field Logbook. The Electronic balance is calibrated every morning and precision tested with an object of known weight.

\section{Overview:}

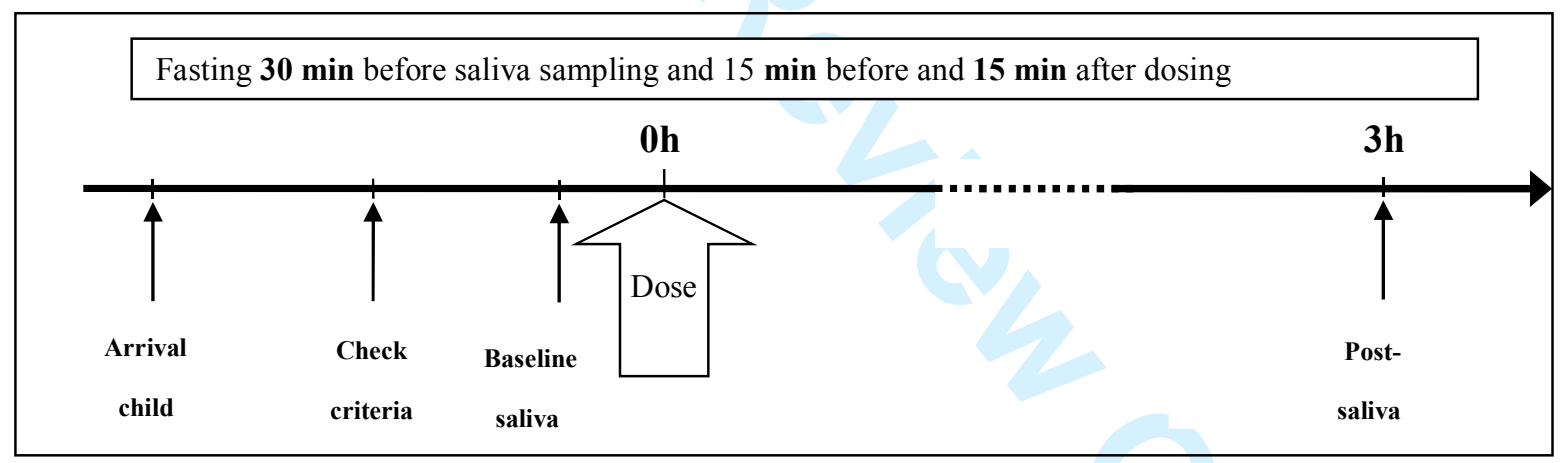

1) Checking criteria and observing fasting before baseline saliva sampling (OBS)

a) Check criteria: child must have passed registration and anthropometry.

b) Observe that child is fasting 30 minutes prior to saliva sampling.

c) Make sure Deuterium Data Collection Sheet is correctly filled in.

\section{2) Baseline saliva sampling (SAL)}

a) Confirm that child has been fasting $30 \mathrm{~min}$ prior to baseline saliva sampling.

b) Mark (with pen) a $2 \mathrm{ml}$ cryotube with o-ring and red cap with study-ID of child: T\#\#\#\#.

c) Explain procedure to caretaker.

d) Wipe the mouth of the child with dispensable paper tissue before start. 
e) Wear new dry gloves before collection. Any kind of fluid on fingers can contaminate results.

f) Collect saliva out of bright sunlight with an already prepared cotton-stick ${ }^{1}$. Systematically collect saliva with cotton stick with one hand while the other hand gently closes the mouth of the child. Two persons might be needed.

g) When first cotton stick is introduced in child's mouth start clock to time collection time.

h) Remove the cotton now soaked with saliva from cotton stick and extract saliva using the plunger from a new $10 \mathrm{ml}$ syringe into cryotube. Close the lid well immediately.

i) It is often necessary to repeat collection procedure a number of times to obtain sufficient saliva.

j) Target volume is $1 \mathrm{ml}$. Absolute minimum volume is $0,5 \mathrm{ml}$.

k) As long as volume of $0.5 \mathrm{ml}$ saliva has not been reached collection must be continued. If $0.5 \mathrm{ml}$ saliva or more has been collected after 10 minutes collection is discontinued. (NB: it should be a very rare situation if collection of saliva must be given up before reaching $0.5 \mathrm{ml}$ )

1) The same $10 \mathrm{ml}$ syringe and plunger can be used for same saliva sample. If syringe is polluted a new syringe is needed. While collecting saliva the syringe is placed on a clean paper tissue. Paper tissues are changed if wet and always between children.

m) Label cryotube with pre-printed labels: At inclusion T\#\#\#\#-S-ZERO-IN and at 3 months T\#\#\#\#-SZERO-EX.

n) Immediately place baseline saliva sample in small zip locked plastic bag placed in "low abundance" cold bag $\left(4^{\circ} \mathrm{C}\right)$. All small bags of baseline saliva sampling are collected in a big zip locked bag to separate baseline from post dose saliva samples.

o) Discard cotton-sticks, syringe and gloves.

p) Make sure Deuterium Data Collection Sheet is correctly filled in.

\section{3) Observe fasting before dosing (OBS)}

a) Child must be confirmed fasting for min. 15 min prior to dosing

b) Make sure Deuterium Data Collection Sheet is correctly filled in.

\section{4) Deuterium dosing (DOSE)}

a) Carefully note all results continuously as indicated on the Deuterium data collection form.

b) Confirm that child has been fasting $15 \mathrm{~min}$. prior to dose administration.

c) Label a $2 \mathrm{ml}$ cryotube with o-ring and yellow cap: T\#\#\#\#-ISD-IN and at 3 months T\#\#\#\#-ISD-EX.

d) Explain caretaker procedure and allow time to play and interact with child.

\footnotetext{
${ }^{1}$ Cotton sticks are prepared with an extra layer of cotton. Cotton sticks must be prepared wearing new gloves and away from the daily activities in the hangar to avoid contamination with D2O.
} 
e) Wear new gloves. Get Dose-Bottles with DDS from cold bag. Always first use Dose-Bottles with most "field-days" indicated on label.

f) Mix by turning Dose-Bottle upside-down systematically 15 times.

g) Draw $10 \mathrm{ml}$ of DDS into a new $10 \mathrm{ml}$ syringe using a 19G needle. The content in the syringe is now an individual study dose (ISD). If syringe is not completely dry on outside wipe with paper tissue that is immediately disposed.

h) Place the full syringe in a sealed plastic bag together with 5 new pieces of gauze. Make sure no fluid is squeezed out of syringe while handling.

i) With a single use plastic pipette dispense the remaining approx. $2 \mathrm{~mL}$ from the Dose-Bottle into a labelled cryo-tube. Dispose the pipette after use.

j) All ISD samples from same day are placed in a small zip plastic bag. ISD samples have a high concentration of D2O and must never be stored with saliva samples. ISD sample are placed in "high abundance" cold bag $\left(4^{\circ} \mathrm{C}\right)$ also used for Dose-Bottles.

k) Place plastic container on scale and Tare scale. Place plastic bag with content in plastic container. Make sure that plastic bag is completely inside the plastic container. Weigh plastic bag with content with two decimals precision.

1) Dry the infant around the mouth with a paper tissue before dosing is initiated. Dispose tissue.

m) Be prepared for collecting any ISD spillage during administration on the pre-weighed tissues (gauzes). Pure drooling to be collected on disposable paper tissue.

n) Administer ISD slowly and precisely in the corner of the mouth. Collect ISD spillage on gauze. Wet gauze is placed in plastic bag and replaced with a dry piece of gauze. Plastic bag is always kept closed. 2 persons will often be needed for the procedure.

o) If 5 pieces of gauze is not sufficient extra gauze (that has been pre-weighed) are used.

p) After administration tare scale with plastic container. Place plastic bag with all content previously being weighed (ISD syringe +5 pieces of gauze) in container and re-weigh. Note result on data collection form. If extra gauze has been used the procedure is repeated here. The difference in weight of bag with content before and after administration $=$ weight of dose in child.

q) Note the exact time of end of dosing in data collection form.

r) Discard gloves and all material used.

\section{5) Post dosing observation (OBS)}

a) The child must be observed 15 min post dose fasting. If the child is regurgitating in this time period it should be noted in the data collection form.

6) Observing fasting before post dose saliva sampling (OBS) 
a) The child must be observed fasting $30 \mathrm{~min}$. before post dose saliva sample.

b) Make sure Deuterium Data Collection Sheet is correctly filled in.

\section{7) Post dose saliva sampling (SAL)}

a) Starting exactly 3 hours after completion of D2O dosing the post dose saliva sample is collected following exactly the same steps as for baseline saliva collection. Use cryotube with o-ring and green cap. Label Post dose saliva sample T\#\#\#\#-S-POST-IN and at 3 months T\#\#\#\#-S-POST-EX

b) Immediately place post dose saliva sample in small zip locked plastic bag placed in "low abundance" cold bag $\left(4^{\circ} \mathrm{C}\right)$. All small bags of post dose saliva sampling are collected in a big zip locked bag to separate baseline from post dose saliva samples.

\section{8) Central Lab}

a) At the end of the day all samples are transported to central lab in cold bags and as fast as possible frozen $\left(-20^{\circ} \mathrm{C}\right)$ until analysis to minimise bacterial growth

\section{9) Cotton stick preparation}

a) Cotton sticks are prepared in the morning in the saliva room.

b) 20 cotton sticks are prepared in a new plastic bag. More bags can be prepared at the time.

c) Once removed cotton sticks must not be reintroduced in plastic bag.

\section{Field equipment needed}

In field: Saliva sampling
Cotton sticks with extra cotton
$10 \mathrm{ml}$ syringes
Disposable paper tissues
$2 \mathrm{ml}$ cryotubes with labels
Gloves
Zip-lock plastic bag
Stop watch
Cold-chain

In field: Administration/sampling of D2O Electronic balance (precision 0.01) $10 \mathrm{~mL}$ syringes Zip-lock plastic bag $19 \mathrm{G}$ needle Safety box for disposed needles $2 \mathrm{ml}$ cryotubes with labels Disposable paper tissues Gaze-tissue approx. 7.5 X $7.5 \mathrm{~cm}$ (non-sterile) Dose-bottles 
ONLINE SUPPLEMENTAL MATERIAL 3

Zero SALIVA: $\quad$ A1.Fasting $30 \mathrm{~min}$. before saliva collection? $\square \quad 0$. No $\square$ 1. Yes

A2. Collection time from first cotton-stick in mouth to full cryotube : $\min$.

A3. Number of Cotton-balls extracted?

A4. How much saliva was collected: $\mathrm{ml}$
DEUTERIUM:
B1. Fasting $15 \mathrm{~min}$. before dosing?
0. No
1. Yes

B2. DDS-\#

B3. Time when starting dosing $(\mathrm{hh} / \mathrm{mm})$

B4. WEIGHT BEFORE (weight of kit before dosing) gr. (XX.XX)

B5. WEIGHT AFTER (weight of kit after dosing) gr.(XX.XX)

B6. If extra tissues weight before: g B7. If extra tissues weight after:

B8. Was full dose administered to child? $\square$ 0. No $\square$ 1. Yes

B9. Was there spillage on gauze?

$\square$ 0. No

1. Yes

B10. Spillage outside gauze?

$\square$ None $\square$ 1-3 drops $\square>3$ drops $-0.5 \mathrm{ml} \quad \square>0.5-1 \mathrm{ml} \quad \square>1 \mathrm{ml}$

B11. Comments for administration if any (max 80 charaters)

B12. Dose administered by full name + ID number :

B13. Time when finishing dosing: (hh/mm)

B14 collect post saliva at $(\mathrm{hh} / \mathrm{mm})$

B15. Did child regurgitate within 15 minutes of receiving D20?

0. No

$\square$ 1. Yes

B16. Has child been observed fasting 15 min after saliva collection?

0. No

1. Yes

POST SALIVA: C1.Child fasting $30 \mathrm{~min}$. before saliva collection?

0. No $\square$ 1. Yes

C2. Collection time from first cotton-ball in mouth till cryotube full : $\min$.

C3. Number of Cotton-balls extracted? C4. How much saliva was collected: $\mathrm{ml}$

C5. Time when finishing saliva collection: $(\mathrm{hh} / \mathrm{mm})$

B6. Comments for saliva collection zero and post-dose any (max 80 charaters) 